\title{
Utilização da farinha de feijão-caupi (Vigna unguiculata L. Walp) na elaboração de produtos de panificação
}

\author{
Utilization of cowpea flour in the development of bakery products \\ Karoline de Macêdo Gonçalves FROTA ${ }^{1}$, Marcelo Antonio MORGANO², Marta Gomes da SILVA², \\ Marcos Antonio da Mota ARAÚJO ${ }^{3}$, Regilda Saraiva dos Reis MOREIRA-ARAÚJO ${ }^{1 \star}$
}

\begin{abstract}
Resumo
Este trabalho teve como objetivo enriquecer produtos de panificação do tipo biscoito e rocambole com farinha de feijão-caupi (FFC), avaliar sua aceitabilidade e composição química, incluindo o conteúdo dos minerais (ferro, zinco, magnésio, potássio e fósforo) e das vitaminas (tiamina e piridoxina). Foram desenvolvidas três formulações de biscoito contendo 10, 20 e 30\% FFC e duas formulações de rocambole contendo 10 e $20 \%$ FFC. Observou-se um aumento no teor protéico do biscoito $30 \%$ FFC e do rocambole $20 \%$ FFC e na quantidade de cinzas dos biscoitos 20 e 30\% FFC e rocambole 20\% FFC, quando comparados às formulações padrão. O teor dos minerais analisados e de piridoxina aumentou à medida que FFC foi adicionada, enquanto a concentração de tiamina aumentou somente no rocambole $20 \%$ FFC. O biscoito com $10 \%$ FFC apresentou maior aceitação (84,4\%), dentre os biscoitos formulados com FFC, além disso, os rocamboles com 10 e $20 \%$ FFC tiveram boa aceitação ( 86,7 e $77,8 \%$, respectivamente). Todas as formulações contendo FFC tiveram notas superiores a 6 , mostrando que os produtos foram aceitos sensorialmente. Desta forma, a adição de FFC visando melhorar o valor nutritivo de formulações à base de cereais é viável.

Palavras-chave: panificação; feijão-caupi; biscoito; rocambole; composição química.
\end{abstract}

\begin{abstract}
This work had as objective to enrich bakery products (biscuit and rocambole or Brazilian roll) with cowpea flour (CF) to analyze their acceptability and chemical composition including mineral contents (iron, zinc, magnesium, potassium, and phosphorus) and vitamins (thiamine and pyridoxine). Three formulations of biscuits containing 10,20, and 30\% CF and two formulations of Brazilian rolls with 10 and $20 \%$ CF were developed. It was observed an increase in the protein contents of the $30 \%$ CF biscuits and $20 \%$ CF Brazilian roll, as well as in the ash value of 20 and $30 \%$ CF biscuits and $20 \%$ CF Brazilian roll, when compared to a standard formulation. The concentration of minerals and pyridoxine analyzed increased with the addition of CF. It was also observed an increase in the thiamine concentration of $20 \%$ CF Brazilian roll. 10\% CF Biscuits presented the major acceptance (84.4\%) among the biscuits formulated with CF. In addition, the 10 e $20 \%$ CF Brazilian rolls also had a good acceptance (86.7 and $77.8 \%$, respectively). All formulations developed with CF presented scores above six indicating that the products were sensory accepted. Therefore, it can be said that the addition of CF with the objective to improve the nutritive value of formulations based on cereals is feasible.
\end{abstract}

Keywords: bakery; cowpea; biscuit; rocambole or Brazilian roll; chemical composition.

\section{Introdução}

O Brasil encontra-se entre os três principais produtores mundiais de feijão-caupi, acompanhando Nigéria e Niger (QUIN, 1997). No Brasil, o feijão-caupi é cultivado predominantemente no sertão semiárido da região Nordeste e em pequenas áreas na Amazônia (MAIA, 1996). No Nordeste, a produção e a produtividade são de 429.375 t e $303,5 \mathrm{~kg} / \mathrm{ha}$, respectivamente. Os maiores produtores são os Estados do Ceará, Piauí, Bahia e Maranhão (IBGE, 1993-2000).

O feijão-caupi (Vigna unguiculata L. Walp.), comumente chamado de feijão-de-corda ou feijão-macassar, constitui alimento básico para as populações de baixa renda do nordeste brasileiro, sendo ainda uma das principais fontes de renda e emprego desta região. Dentre os diferentes produtos agrícolas encontrados nas regiões tropicais, o caupi se destaca pelo alto valor nutritivo, além de seu baixo custo de produção (EMBRAPA MEIO-NORTE, 2003).

Esta leguminosa apresenta um importante papel na nutrição humana por constituir uma importante fonte de proteínas, carboidratos, destacando-se pelo alto teor de fibras alimentares, vitaminas e minerais, além de possuir baixa quantidade de lipídios (EMBRAPA MEIO-NORTE, 2003).

O feijão, além de aumentar o conteúdo protéico na alimentação, contribui para melhorar sua qualidade na dieta, quando constituída predominantemente de leguminosas e cereais, porque além de ser uma excelente fonte de proteínas

Recebido para publicação em 28/1/2008

Aceito para publicação em 5/1/2009 (003183)

${ }^{1}$ Departamento de Nutrição, Universidade Federal do Piauí - UFPI, CEP 64049-550, Teresina - PI, Brasil, E-mail: regilda@ufpi.br; karolfrota@usp.br

${ }^{2}$ Centro de Ciência e Qualidade de Alimentos- ITAL, Caixa Postal 139 CEP 13070-178, Campinas -SP, Brasil

${ }^{3}$ Fundação Municipal de Saúde, GEPLAN, CEP 64025-530, Teresina - PI, Brasil

${ }^{*}$ A quem a correspondência deve ser enviada 
(23 a 25\% em média) apresenta todos os aminoácidos essenciais, em especial, lisina, uma vez que os cereais são deficientes neste aminoácido (IQBAL; KHALIL; SHAH, 2003). Portanto, o desenvolvimento de produtos alimentícios à base de cereais, com a substituição parcial deste por farinha de feijão-caupi, pode proporcionar um enriquecimento nutricional de alimentos tradicionalmente disponíveis no mercado.

O desenvolvimento de alimentos enriquecidos tem grande importância não só para a indústria de alimentos, como também para elevar a qualidade da alimentação e nutrição da população, pois se pode criar novos produtos ou melhorar os já existentes com composições balanceadas em relação a alguns nutrientes, melhorando, dessa forma, o valor nutritivo de diversos alimentos disponíveis no mercado (CARDOSOSANTIAGO et al., 2001; MOREIRA-ARAÚJO et al., 2002; MOREIRA-ARAÚJO; ARAÚJO; ARÊAS, 2008).

Produtos como biscoito e rocambole foram escolhidos para o enriquecimento, pela importância dos produtos de panificação e confeitaria na lista de compras dos brasileiros, ocupando a terceira colocação e representando, em média, 12\% do orçamento familiar para alimentação (ABIP, 2008). Portanto, melhorar a qualidade nutricional dos produtos que fazem parte do hábito de consumo da população é uma importante estratégia para atender aos interesses dos consumidores por produtos com melhor valor nutricional e/ou benefícios à saúde.

O presente trabalho teve como objetivo utilizar a farinha de feijão-caupi (FFC) em substituição à farinha de trigo em formulações de biscoitos e rocamboles, aumentando o valor nutricional e mantendo as boas características de aceitação.

\section{Material e métodos}

\subsection{Matéria-prima}

A amostra de feijão-caupi (Vigna unguiculata L. Walp), cultivar Tracuateua - 235, foi obtida em um único lote da Empresa Brasileira de Pesquisa Agropecuária (EMBRAPA MEIO-NORTE), Teresina, PI, Brasil. Os demais ingredientes, como farinha de trigo, arroz, ovo, óleo, margarina, leite, sal, açúcar, mel e fermento biológico, utilizados na produção das formulações foram obtidos no comércio local de Teresina.

\subsection{Métodos}

\section{Processamento da matéria-prima}

Para a obtenção da farinha de feijão-caupi (FFC), inicialmente colocou-se o feijão de molho em água destilada 1:2 (p/v) por 1 hora, sendo posteriormente removidos seus tegumentos. Seguiram-se secagem em estufa ventilada modelo 314D242 (Quimis, Brasil) a $50^{\circ} \mathrm{C}$, por 24 horas, e moagem em moinho semi-industrial (Fritsch). A farinha foi armazenada em sacos de polietileno sob refrigeração até o momento de ser utilizada na produção das formulações.

\section{Desenvolvimento das formulações}

As formulações foram desenvolvidas por meio de prétestes em laboratório, utilizando como base uma receita convencional de biscoito e de massa de rocambole. Foram preparadas formulações de biscoitos e rocamboles com adição de diferentes quantidades de farinha de feijão-caupi (FFC), variando-se as proporções entre os ingredientes bem como o tempo e a temperatura de cozimento a fim de se obterem opções viáveis para a fase seguinte (análise sensorial dos produtos). $\mathrm{O}$ critério de seleção das amostras teste foi baseado na opinião dos pesquisadores do Laboratório de Bromatologia, Estudo Experimental e Análise Sensorial de Alimentos da Universidade Federal do Piauí (UFPI).

Obtiveram-se três formulações de biscoito e duas de rocambole, diferindo principalmente na quantidade de FFC adicionada em substituição à farinha de trigo e/ou arroz cozido (Tabela 1 e 2).

Os biscoitos foram preparados primeiramente pela mistura manual de todos os ingredientes. Depois de homogeneizada, a massa foi cortada em pesos de $8 \mathrm{~g}$ aproximadamente por meio de esferas e, em seguida, enrolada manualmente. Os biscoitos crus foram distribuídos em tabuleiros retangulares e assados em forno doméstico à temperatura aproximada de $200{ }^{\circ} \mathrm{C}$, por 16 minutos. Após assados, os biscoitos foram deixados para resfriar em ambiente aberto e, então, armazenados em recipientes plásticos.

Os ingredientes para formulação de rocambole foram misturados em liquidificador e posteriormente despejados sobre forma de alumínio untada com margarina e levada para assar

Tabela 1. Formulações de biscoito padrão, 10, 20 e 30\% FFC.

\begin{tabular}{lcccc}
\hline $\begin{array}{c}\text { Ingrediente/ } \\
\text { formulação }\end{array}$ & $\begin{array}{c}\text { Padrão } \\
(\%)\end{array}$ & $\begin{array}{c}10 \% \text { FFC } \\
(\%)\end{array}$ & $\begin{array}{c}20 \% \text { FFC } \\
(\%)\end{array}$ & $\begin{array}{c}30 \% \text { FFC } \\
(\%)\end{array}$ \\
\hline Farinha de feijão-caupi & - & 10,0 & 20,0 & 30,0 \\
Farinha de trigo & 56,0 & 46,0 & 36,0 & 26,0 \\
Margarina & 10,0 & 10,0 & 10,0 & 10,0 \\
Ovo & 19,2 & 19,2 & 19,2 & 19,2 \\
Mel & 4,4 & 4,4 & 4,4 & 4,4 \\
Açúcar & 10,3 & 10,3 & 10,3 & 10,3 \\
Sal & 0,1 & 0,1 & 0,1 & 0,1 \\
\hline
\end{tabular}

Tabela 2. Formulações de rocambole padrão, 10 e 20\% FFC.

\begin{tabular}{lccc}
\hline Ingrediente/formulação & Padrão (\%) & 10\% FFC (\%) & 20\% FFC (\%) \\
\hline Farinha de feijão-caupi & - & 10,0 & 20,0 \\
Arroz cozido & 31,6 & 22,9 & 15,4 \\
Farinha de trigo & 7,8 & 6,5 & 4,0 \\
Leite & 11,7 & 11,7 & 11,7 \\
Óleo & 11,7 & 11,7 & 11,7 \\
Fermento biológico & 0,5 & 0,5 & 0,5 \\
Gema & 13,5 & 13,5 & 13,5 \\
Sal & 0,1 & 0,1 & 0,1 \\
Água & 23,1 & 23,1 & 23,1 \\
\hline
\end{tabular}


em forno doméstico à temperatura de $180^{\circ} \mathrm{C}$ por 12 minutos. Depois de a massa estar pronta, um recheio com frango desfiado foi acrescentado e a massa enrolada.

\section{Composição química}

As formulações de biscoitos e rocambole foram analisadas com relação à composição química, determinando-se os teores de umidade, cinzas, proteínas e lipídios.

A umidade foi determinada após secagem em estufa modelo 314D242 (Quimis, Brasil) a $105^{\circ} \mathrm{C}$ até obtenção de peso constante; o teor de cinzas foi determinado após calcinação das amostras em mufla modelo Q-318M21 (Quimis, Brasil) a $550{ }^{\circ} \mathrm{C}$ por 12 horas; a concentração de proteínas foi determinada pelo método Micro-Kjeldahl, com fator de conversão de 6,25; e o teor de lipídios foi determinado por extração com éter de petróleo em aparelho Soxhlet modelo TE-044 (Tecnal, Brasil) (AOAC, 1990).

\section{Teor de minerais}

Os minerais fósforo, ferro, potássio, zinco e magnésio foram determinados usando-se a técnica de espectrometria de emissão atômica com fonte de plasma indutivamente acoplado (ICP OES), segundo Horwitz (2000), adaptada, após mineralização das amostras em forno mufla a $450{ }^{\circ} \mathrm{C}$. Estas análises foram realizadas no Centro de Ciência e Qualidade de Alimentos/ ITAL/SP, em triplicata.

\section{Conteúdo de vitaminas}

As vitaminas tiamina e piridoxina foram determinadas por cromatografia líquida de alta eficiência (HPLC).

\section{Tiamina}

Após hidrólise ácida e enzimática com diastase e papaína (VAN DE WEERDHOF; WIERSUN; REISSENWEBER; 1973; HORWITZ, 2005a), a tiamina foi determinada por cromatografia líquida, usando-se detector de fluorescência, com comprimento de onda de excitação de 362 nm e emissão de 464 nm; coluna de fase reversa C18 (Merck) de $125 \times 4 \mathrm{~mm}, 5 \mathrm{~m}$, fase móvel $26,8 \mathrm{mM}$ de $\mathrm{KCl}$ em solução $15 \%$ de metanol, sistema isocrático com vazão de $0,5 \mathrm{~mL} / \mathrm{min}$. A quantificação foi realizada por padronização externa e derivação pós-coluna com ferricianeto de potássio em meio alcalino (VAN DE WEERDHOF; WIERSUN; REISSENWEBER, 1973; HORWITZ, 2005b).

\section{Piridoxina}

Após hidrólise ácida segundo Horwitz (2005a), a piridoxina foi determinada por cromatografia líquida, usando-se um detector de fluorescência, comprimento de onda de excitação de 295 nm e emissão de $405 \mathrm{~nm}$; coluna de fase reversa C18 de $125 \times 4 \mathrm{~mm}, 5 \mathrm{~m}$, fase móvel solução de fosfato de potássio monobásico 0,033 M, pH 2,2 em sistema isocrático, vazão de $0,7 \mathrm{~mL} / \mathrm{min}$ e quantificação por padronização externa com cloridrato de piridoxina (HORWITZ, 2005c; GREGORY; KIRK, 1978).
As determinações de vitaminas foram realizadas no Centro de Ciência e Qualidade de Alimentos/ITAL/SP, em triplicata.

\section{Teste de aceitabilidade}

Foram recrutados voluntários para comporem a equipe sensorial dentre funcionários e estudantes de ambos os sexos e com idade de 18 a 50 anos da Universidade Federal do Piauí.

As amostras foram servidas aleatoriamente aos julgadores em pratos de plásticos, com quantidades padronizadas e codificadas com 3 dígitos, obtidos de uma tabela de números aleatórios (PEDRERO; PANGBORN, 1989). Foi fornecida água aos provadores e solicitou-se que enxaguassem a boca entre as trocas das amostras (FERREIRA, 2000). O teste foi realizado entre 9 horas 30 minutos e 11 horas no Laboratório de Análise Sensorial de Alimentos da Universidade Federal do Piauí UFPI, que dispõe de cabines individuais com luz branca.

Para verificar a aceitação global dos produtos, foi aplicada a 45 julgadores não treinados uma escala hedônica de 9 pontos, cujos extremos correspondem a desgostei muitíssimo (1) e gostei muitíssimo (9). As amostras foram apresentadas aos julgadores e foi solicitado que as analisassem com relação à escala proposta.

\section{Análise estatística}

Os dados obtidos na análise sensorial, na composição centesimal, no conteúdo de minerais e vitaminas foram analisados por ANOVA, adotando-se nível de significância de $5 \%$ e contraste entre as médias pelo teste de Tukey para identificar a diferença entre as formulações.

Esta pesquisa teve seu projeto avaliado e aprovado pelo Comitê de Ética em Pesquisa da Universidade Federal do Piauí.

\section{Resultados e discussão}

\subsection{Composição química}

A composição química das formulações padrão e adicionadas de FFC está apresentada na Tabela 3. Os resultados apresentados foram compatíveis com valores reportados para biscoitos com adição de farinha mista em outro estudo (GUILHERME; JOKL, 2005).

Para as formulações de biscoitos, não houve diferença significativa no teor de umidade e lipídios. Os teores de cinzas e proteínas aumentaram significativamente no biscoito com $30 \%$ de FFC, podendo ser explicado pelo elevado conteúdo de minerais presentes nessa farinha. Apesar dos biscoitos com 10 e $20 \%$ FFC não apresentarem um aumento no teor protéico, a substituição parcial da farinha de trigo por farinha de feijão pode melhorar o perfil de aminoácidos destes produtos, pois os cereais são deficientes no aminoácido lisina. De acordo com Frota (2008), o feijão-caupi apresenta em média 6,8 g.100 g $\mathrm{g}^{-1}$ de lisina, valor superior à recomendação da FAO/WHO (1991) para crianças de 2 a 5 anos de $5,8 \mathrm{~g} .100 \mathrm{~g}^{-1}$. O aumento do teor de proteínas nas formulações com adição de FFC pode 
ser justificado pela quantidade de proteína presente no feijãocaupi. Como observado na Tabela 3 , a farinha de feijão-caupi (FFC) apresenta em média 24,3 g.100 g-1 de proteína em base úmida, o dobro da quantidade encontrada na farinha de trigo $\left(11,66\right.$ g. $\left.100 \mathrm{~g}^{-1}\right)$ e 11 vezes a quantidade presente no arroz cozido (2,05 g.100 g-1) (TBCAUSP, 1998).

Para os rocamboles não foi observada diferença na quantidade de lipídio. O teor de umidade foi significativamente menor no rocambole com $20 \%$ de FFC. Isto pode ser explicado pela quantidade de água desprendida durante a cocção da massa, pois esta formulação necessitou de maior tempo (15 minutos) para completar a cocção comparada à formulação padrão (12 minutos). O conteúdo de cinzas e proteínas também aumentou significativamente no rocambole $20 \%$ FFC como foi observado nas formulações de biscoitos com maior adição de FFC.

\subsection{Teor de minerais}

Os teores dos minerais fósforo, ferro, potássio, magnésio e zinco aumentaram significativamente com a adição de farinha de feijão-caupi (Tabela 4). Este incremento foi importante principalmente para os minerais ferro e zinco. O ferro porque sua deficiência é a mais comum e a mais grave deficiência de micronutrientes em todo o mundo (OMS/OPAS, 2001), estimando-se que há mais de dois bilhões de pessoas no mundo com anemia, o que representa $1 / 3$ da população mundial. $O$ zinco, pois sua deficiência marginal é um problema nutricional comum, principalmente em países em desenvolvimento, acreditando-se que sua existência, mesmo não associada a uma característica clínica específica, já produziria sérias consequências para a saúde infantil (BRUTTA et al., 1999; MAHALANABIS; BHAN, 2001). Cerca de 800 mil mortes de crianças por ano são atribuídas à deficiência de zinco (BLACK, 2003).

Comparando-se a ingestão dietética de referência (DRI) às quantidades de minerais presentes em $100 \mathrm{~g}$ do biscoito com $30 \%$ de FFC, encontram-se atendidas 15,6\% da DRI para o ferro, $25 \%$ para o zinco, $30 \%$ para o magnésio e $76 \%$ para o fósforo. A formulação padrão de biscoito atinge apenas $6,6 \%$ da DRI para ferro, $8,4 \%$ para o zinco, $12,5 \%$ para magnésio e $63 \%$ para o fósforo, considerando-se a ingestão diária de referência para crianças de 4 a 8 anos.

Com a adição de $30 \%$ de FFC no biscoito, aumenta em 2,4 vezes a quantidade de ferro, em quase 3 vezes a do zinco e em 2,4 vezes a do magnésio, quando comparado ao biscoito padrão. $\mathrm{O}$ fósforo não representa preocupação quanto à cobertura das necessidades nutricionais, pois mesmo a formulação padrão de biscoito já contém elevado teor deste micronutriente.

Em $100 \mathrm{~g}$ de rocambole com adição de $20 \%$ de FFC encontram-se supridas $12 \%$ das DRIs para o ferro, $19 \%$ para o

Tabela 3. Composição química (g.100 g $\mathrm{g}^{-1}$ ) da farinha de feijão caupi (FFC), dos biscoitos padrão, 10,20 e $30 \%$ FFC e rocambole padrão, 10 e $20 \%$ FFC.

\begin{tabular}{lllcc}
\hline \multicolumn{1}{c}{ Formulações } & Umidade & Cinzas & Proteínas & Lipídios \\
\hline FFC & $9,83(0,25)$ & $3,14(0,02)$ & $24,28(0,12)$ & $1,49(0,02)$ \\
Biscoito padrão & $7,62(0,28)^{\mathrm{NS}}$ & $2,48(0,15)^{\mathrm{a}}$ & $9,26(0,40)^{\mathrm{a}}$ & $12,14(1,25)^{\mathrm{NS}}$ \\
Biscoito 10\% FFC & $7,63(0,08)^{\mathrm{NS}}$ & $2,98(0,13)^{\mathrm{a}}$ & $10,32(1,01)^{\mathrm{ab}}$ & $11,96(1,07)^{\mathrm{NS}}$ \\
Biscoito 20\% FFC & $7,60(0,30)^{\mathrm{NS}}$ & $3,96(0,19)^{\mathrm{b}}$ & $11,68(0,93)^{\mathrm{ab}}$ & $12,11(0,81)^{\mathrm{NS}}$ \\
Biscoito 30\% FFC & $7,71(0,38)^{\mathrm{NS}}$ & $4,70(0,26)^{\mathrm{b}}$ & $12,38(0,37)^{\mathrm{b}}$ & $12,14(0,16)^{\mathrm{NS}}$ \\
Rocambole padrão & $61,64(1,28)^{\mathrm{b}}$ & $2,52(0,13)^{\mathrm{a}}$ & $5,56(0,38)^{\mathrm{a}}$ & $12,35(1,87)^{\mathrm{NS}}$ \\
Rocambole 10\% FFC & $58,37(1,85)^{\mathrm{ab}}$ & $2,83(0,21)^{\mathrm{a}}$ & $7,14(0,76)^{\mathrm{ab}}$ & $11,98(1,38)^{\mathrm{NS}}$ \\
Rocambole 20\% FFC & $53,34(0,46)^{\mathrm{a}}$ & $3,72(0,26)^{\mathrm{b}}$ & $8,58(0,52)^{\mathrm{b}}$ & $11,84(2,44)^{\mathrm{NS}}$ \\
\hline
\end{tabular}

Média (estimativa de desvio-padrão). Letras diferentes na mesma coluna para uma mesma formulação indicam diferença estatística (Teste de Tukey), NS - diferença não significativa.

Tabela 4. Teor de minerais da farinha de feijão-caupi (FFC), dos biscoitos padrão, 10, 20 e 30\% FFC e rocamboles padrão, 10 e $20 \%$ FFC $\left(\mathrm{mg} .100 \mathrm{~g}^{-1}\right)$, ingestão dietética de referência (DRI) em mg/dia.

\begin{tabular}{lccccc}
\hline \multicolumn{1}{c}{ Formulações } & Fósforo & Ferro & Potássio & Magnésio & Zinco \\
\hline FFC & $437,00(6,40)$ & $4,52(0,03)$ & $1036,40(25,40)$ & $47,20(0,10)$ & $3,74(0,50)$ \\
Biscoito padrão & $316,3(2,90)^{\mathrm{a}}$ & $0,66(0,02)^{\mathrm{a}}$ & $141,90(1,60)^{\mathrm{a}}$ & $16,23(0,04)^{\mathrm{a}}$ & $0,42(0,01)^{\mathrm{a}}$ \\
Biscoito 10\% FFC & $335,40(8,10)^{\mathrm{b}}$ & $0,97(0,04)^{\mathrm{b}}$ & $253,20(3,00)^{\mathrm{b}}$ & $25,80(0,60)^{\mathrm{b}}$ & $0,70(0,02)^{\mathrm{b}}$ \\
Biscoito 20\% FFC & $348,00(12,10)^{\mathrm{bc}}$ & $1,26(0,03)^{\mathrm{c}}$ & $347,70(4,10)^{\mathrm{c}}$ & $34,20(0,40)^{\mathrm{c}}$ & $1,04(0,01)^{\mathrm{c}}$ \\
Biscoito 30\% FFC & $381,80(1,50)^{\mathrm{c}}$ & $1,56(0,05)^{\mathrm{d}}$ & $453,30(6,20)^{\mathrm{d}}$ & $38,50(2,20)^{\mathrm{d}}$ & $1,28(0,09)^{\mathrm{d}}$ \\
Rocambole padrão & $146,80(4,10)^{\mathrm{a}}$ & $0,58(0,01)^{\mathrm{a}}$ & $72,50(0,30)^{\mathrm{a}}$ & $6,15(0,03)^{\mathrm{a}}$ & $0,42(0,01)^{\mathrm{a}}$ \\
Rocambole 10\% FFC & $170,70(0,40)^{\mathrm{b}}$ & $0,73(0,02)^{\mathrm{b}}$ & $166,60(1,30)^{\mathrm{b}}$ & $15,40(0,50)^{\mathrm{b}}$ & $0,60(0,02)^{\mathrm{b}}$ \\
Rocambole 20\% FFC $^{\mathrm{b}}$ & $197,60(0,90)^{\mathrm{c}}$ & $1,16(0,01)^{\mathrm{c}}$ & $266,80(1,90)^{\mathrm{c}}$ & $27,40(0,10)^{\mathrm{c}}$ & $0,94(0,01)^{\mathrm{c}}$ \\
DRI $^{*}$ & 500 & 10 & - & 130 & 5 \\
\hline
\end{tabular}

Média (estimativa de desvio-padrão). Letras diferentes na mesma coluna para uma mesma formulação indicam diferença estatística (Teste de Tukey). DRI para crianças de 4 a 8 anos (NRC, 2001). 
zinco, $21 \%$ para o magnésio e $39 \%$ para o fósforo. Na formulação padrão, o ferro atinge apenas $5,8 \%$ da DRI, na faixa etária de 4 a 8 anos, $8,4 \%$ para o zinco, $4,7 \%$ para o magnésio e $29,4 \%$ para o fósforo. Isto mostra que a adição de FFC pode realmente melhorar o aporte destes minerais, beneficiando principalmente as crianças, que são as mais prejudicadas pela deficiência de micronutrientes.

Segundo a Portaria no 31, de 13 de janeiro de 1998 da ANVISA (BRASIL, 1998), alimentos sólidos adicionados de nutrientes que forneçam no mínimo $15 \%$ da DRI de referência podem receber o claim "FONTE”. Por isso, o biscoito com $30 \%$ de FFC e o rocambole com $20 \%$ de FFC podem ser considerados "fontes" de ferro, zinco, magnésio e fósforo com exceção do ferro para o rocambole com $20 \%$ de FFC, considerando-se as DRIs para crianças de 4 a 8 anos.

\subsection{Conteúdo de vitaminas}

Os teores das vitaminas tiamina e piridoxina da farinha de feijão-caupi e das formulações de biscoito e rocambole padrão e adicionados de FFC são apresentadas na Tabela 5.

O conteúdo de tiamina presente na farinha de feijão-caupi (FFC) foi de $0,13 \mathrm{mg} .100 \mathrm{~g}^{-1}$, valor próximo ao encontrado por Padovani et al. (2007) em feijão preto $\left(0,12 \mathrm{mg} \cdot 100 \mathrm{~g}^{-1}\right)$. No entanto, a quantidade de tiamina do feijão-caupi (Vigna unguiculata L. Walp), cultivar BRS-Tracuateua é inferior ao obtido por Khatoon e Prakash (2004) no feijão-caupi (Vigna catjang), cujo teor de tiamina é de $0,42 \mathrm{mg} .100 \mathrm{~g}^{-1}$ e por Ghavidel e Prakash (2007) que obtiveram 0,64 mg.100 g ${ }^{-1}$ de tiamina na semente de Vigna catjang. Mesmo o teor desta vitamina não sendo tão alto quanto em outras espécies de Vigna, a adição de $20 \%$ de FFC no rocambole proporcionou aumento importante na concentração de tiamina quando comparada às outras formulações. Como a ingestão de referência diária (DRI) da tiamina é 0,6 mg (NRC, 2001), para crianças de 4 a 8 anos, o rocambole com $20 \%$ de FFC fornece $30 \%$ das recomendações.

O conteúdo de piridoxina na FFC foi de 0,60 mg.100 $\mathrm{g}^{-1}$, valor semelhante ao encontrado no feijão-preto $\left(0,59 \mathrm{mg} .100 \mathrm{~g}^{-1}\right)$ (PADOVANI et al., 2007). O teor de piridoxina nos biscoitos e nos rocamboles adicionados de FFC aumentou significativamente

Tabela 5. Teor de tiamina e piridoxina da farinha de feijão-caupi (FFC), dos biscoitos padrão, 10, 20 e 30\% FFC e rocamboles padrão, 10 e $20 \%$ FFC (mg. $\left.100 \mathrm{~g}^{-1}\right)$.

\begin{tabular}{lcc}
\hline \multicolumn{1}{c}{ Formulações } & Tiamina & Piridoxina \\
\hline FFC & $0,13(0,01)$ & $0,60(0,04)$ \\
Biscoito padrão & $\mathrm{Nd}$ & $0,07(0,01)^{\mathrm{a}}$ \\
Biscoito 10\% FFC & $\mathrm{Nd}$ & $0,09(0,01)^{\mathrm{b}}$ \\
Biscoito 20\% FFC & $\mathrm{Nd}$ & $0,13(0,00)^{\mathrm{c}}$ \\
Biscoito 30\% FFC & $\mathrm{Nd}$ & $0,14(0,01)^{\mathrm{d}}$ \\
Rocambole padrão & $\mathrm{Nd}$ & $\mathrm{Nd}$ \\
Rocambole 10\% FFC & $\mathrm{Nd}$ & $\mathrm{Tr}$ \\
Rocambole 20\% FFC & $0,18(0,02)$ & $0,08(0,00)$
\end{tabular}

Média (estimativa de desvio padrão). Letras diferentes na mesma coluna para uma mesma formulação indicam diferença estatística (Teste de Tukey). Tiamina e piridoxina: $\mathrm{Nd}$ = não detectado, menor que $0,03 \mathrm{mg} \cdot 100 \mathrm{~g}^{-1} ; \mathrm{Tr}=$ traço, menor que $0,04 \mathrm{mg} \cdot 100 \mathrm{~g}^{-1}$. à medida que a farinha foi adicionada. O biscoito com $30 \%$ e o rocambole com $20 \%$ de FFC apresentaram maiores concentrações de piridoxina, representando 23 e 13\%, respectivamente, da ingestão de referência diária (DRI) para crianças de 4 a 8 anos, que segundo a National Academic Press (2001) é de 0,6 mg.

\subsection{Teste de aceitabilidade}

Os resultados referentes às notas dos biscoitos padrão e formulados com 10, 20 e 30\% de FFC e rocambole padrão e com adição de 10 e $20 \%$ de FFC obtidas com os testes de aceitabilidade global são apresentados na Tabela 6 .

Todas as formulações com adição de FFC tiveram níveis de aceitação satisfatórios, com médias superiores a 6 (gostei ligeiramente). O biscoito com $10 \%$ de FFC apresentou nota de aceitação significativamente igual ao biscoito padrão. Para os biscoitos com 10, 20 e 30\% de FFC não houve diferença significativa na nota de aceitação entre eles, porém os biscoitos com 20 e $30 \%$ de FFC tiveram notas menores quando comparados ao biscoito padrão. As notas médias de aceitação dos rocamboles com 10 e $20 \%$ de FFC foram estatisticamente iguais, mas diferentes do rocambole padrão.

A aceitabilidade global sofreu uma diminuição gradual nas médias, com aumento nos níveis de adição de FFC, comprovando assim a influência do hábito alimentar sobre a preferência ao produto. Os resultados obtidos na análise sensorial revelaram que o biscoito elaborado com adição de $10 \%$ de FFC teve aceitabilidade igual ao biscoito padrão, enquanto o rocambole com $10 \%$ de FFC foi o mais aceito, sendo inferior apenas ao padrão.

O grau de aceitabilidade dos biscoitos e rocamboles padrão e adicionados de FFC são mostrados nas Figuras 1 e 2.

O biscoito com 10\% de FFC obteve o maior grau de aceitabilidade (84,4\%), dentre as formulações adicionadas de FFC. Os biscoitos com 20 e $30 \%$ de FFC apresentarem graus de aceitação muito próximos, sendo que o biscoito 30\% FFC apresentou qualidade nutricional significativamente superior.

Os percentuais de aceitabilidade dos rocamboles com 10 e $20 \%$ de FFC foram menores que o do rocambole padrão, mas ainda permaneceram bastante elevados. Como os resultados de composição química mostram superioridade do rocambole

Tabela 6. Valores médios de aceitabilidade de biscoito padrão, 10, 20 e $30 \%$ FFC e de rocambole padrão, 10 e $20 \%$ FFC.

\begin{tabular}{lc}
\hline \multicolumn{1}{c}{ Amostras } & Aceitação global (nota) \\
\hline Biscoito padrão & $7,3(1,8)^{\mathrm{a}}$ \\
Biscoito 10\% FFC & $7,0(2,0)^{\mathrm{ab}}$ \\
Biscoito 20\% FFC & $6,1(1,7)^{\mathrm{b}}$ \\
Biscoito 30\% FFC & $6,0(2,2)^{\mathrm{b}}$ \\
Rocambole padrão & $7,8(1,2)^{\mathrm{a}}$ \\
Rocambole 10\% FFC & $6,6(1,6)^{\mathrm{b}}$ \\
Rocambole 20\% FFC & $6,6(1,8)^{\mathrm{b}}$ \\
\hline
\end{tabular}

Média (estimativa de desvio padrão). Letras diferentes na mesma coluna para uma mesma formulação indicam diferença estatística (Teste de Tukey). 


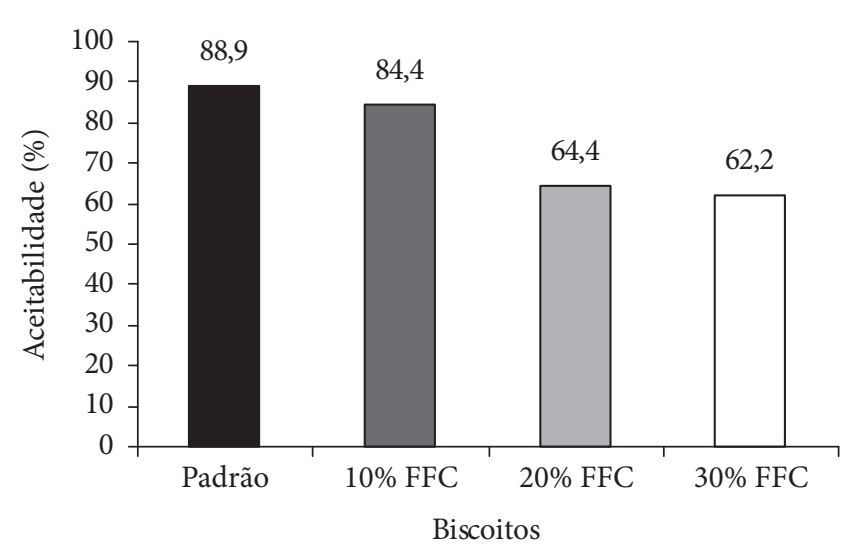

Figura 1. Grau de aceitabilidade dos biscoitos padrão, 10, 20 e $30 \%$ FFC.

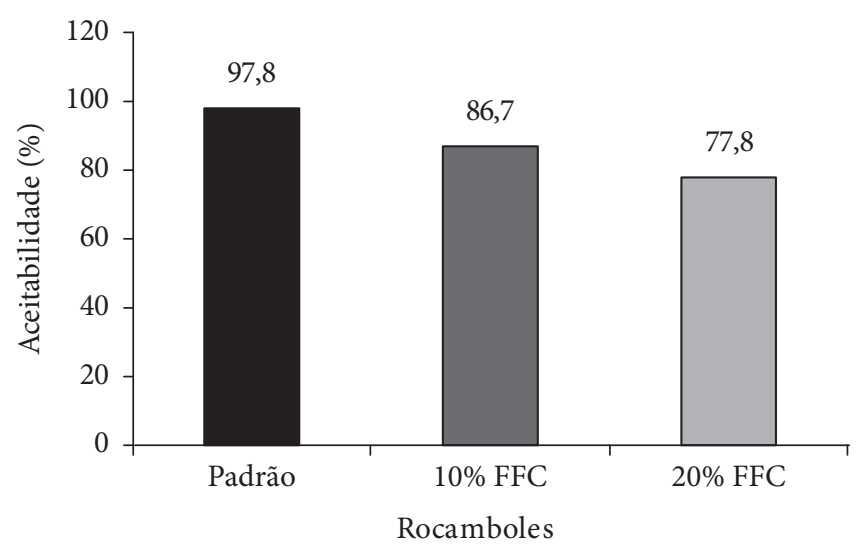

Figura 2. Grau de aceitabilidade dos rocamboles padrão e desenvolvidos com 10 e $20 \%$ de FFC.

com maior adição de farinha (20\%), esta seria uma boa escolha para consumo.

De acordo com Teixeira, Meinert e Barbetta (1987), para que um produto seja considerado como aceito em termos de suas propriedades sensoriais, é necessário que obtenha um índice de aceitabilidade de, no mínimo, 70\% e, neste caso, o biscoito com $10 \%$ de FFC e os rocamboles com 10 e $20 \%$ tiveram boa aceitabilidade. Isso indica que estes produtos podem ser recomendados para consumo da população em geral, visando fornecer um melhor aporte protéico, de ferro, de zinco, de magnésio e de piridoxina.

Como se observa, a adição de farinha de feijão-caupi (FFC) em formulações aceitas sensorialmente pode melhorar significativamente o conteúdo de certas vitaminas e minerais, bem como o teor de proteínas.

\section{Conclusões}

De modo geral, os resultados obtidos para os biscoitos e rocamboles contendo farinhas de feijão-caupi foram considerados satisfatórios, quando comparados às formulações padrão contendo apenas farinha de trigo e/ou arroz.
As formulações com adição de FFC mais aceitas foram os biscoitos e rocamboles com 10\% de FFC (84,4 e 86,7\%, respectivamente).

O emprego da FFC em diferentes proporções contribuiu para elevar a qualidade nutricional, principalmente quanto ao teor de proteínas, dos minerais ferro, zinco, magnésio, potássio e da vitamina piridoxina.

Os resultados do teste sensorial demonstram que é viável adicionar farinha de feijão-caupi visando melhorar o valor nutritivo de certo produtos alimentícios, pois a maioria das formulações apresentou aceitação superior a 70\%.

\section{Agradecimentos}

Ao CNPq pela bolsa concedida, à Empresa Brasileira de Pesquisa Agropecuária (EMBRAPA MEIO-NORTE) por ter doado as amostras de feijão-caupi e ao Instituto de Tecnologia de Alimentos - ITAL/SP pela análise de minerais e vitaminas.

\section{Referências bibliográficas}

ASSOCIAÇÃO BRASILEIRA DAS INDÚSTRIAS DE PANIFICAÇÃO E CONFEITARIA - ABIP. Análise do mercado de pães. Brasília, 2002, 2003. Disponível em: <http://www.abip.org.br>. Acesso em: Setembro 2008.

ASSOCIATION OFFICIAL ANALYTICAL CHEMISTS - AOAC. Official methods of analysis. Washington, 1990.

BLACK, R. Micronutrient deficiency: an underlying cause of morbity and mortality. Bulletin of the World Health Organization, v. 81, n. 2, p. 79, 2003.

BRASIL. Ministério da Saúde. Portaria n. ${ }^{\circ} 31$ de 13 de janeiro de 1998. Aprova o regulamento técnico referente a alimentos adicionados de nutrientes essenciais. Diário Oficial da União, Poder Executivo, Brasília, DF, 16 de Janeiro de 1998.

BRUTTA, Z. A. et al. Prevetion of diarrhea and pneumonia by zinc supplementation in children in developing countries: pooled analysis of randomized controlled trials. Journal of Pediatrics, v. 135, n. 6, p. 689-697, 1999.

CARDOSO-SANTIAGO, R. A.; MOREIRA-ARAUJO, R. S. R.; ARÊAS, J. A. G. The potencial of extruded chickpea, corn and bovine lung for malnutrition program. Innovative Food Science and Emerging Technologies, v. 2, n. 3, p. 203-209, 2001.

EMBRAPA MEIO-NORTE. Cultivo de feijão caupi. Teresina, Julho 2003. Disponível em: <http://www.cpamn.embrapa.br/pesquisa/ graos/FeijaoCaupi/referencias.htm>. Acesso em: Outubro 2007.

FERREIRA, V. L. P. Análise sensorial: testes discriminativos e afetivos. Campinas: Sociedade Brasileira de Ciência e Tecnologia de Alimentos, 2000. p. 73-77. (Manual Série Qualidade).

FOOD AND AGRICULTURE ORGANIZATION - FAO. Protein quality evaluation. Roma, 1991. 66 p. (Food and Nutrition paper, n. 51).

FROTA, K. M. G.; SOARES, R. A. M.; ARÊAS, J. A. G. Composição química do feijão caupi (Vigna unguiculata L. Walp), cultivar BRS-Milênio. Ciência e Tecnologia de Alimentos, v. 28, n. 2, p. 470-476, 2008.

GHAVIDEL, R. A.; PRAKASH, J. The impact of germination and dehulling on nutrients, antinutrients, in vitro iron and calcium bioavailability and in vitro starch and protein digestibility of some legume seeds. Food Science and Technology, v. 40, n. 7, p. 12921299, 2007. 
GREGORY, J. F.; KIRK, J. R. Assessment of storage effects on vitamin B6 stability and bioavailability in dehydrated food systems. Journal of Food Science, v. 43, n. 6, p. 1801-1808, 1978.

GUILHERME, F. F. P.; JOKL, L. Emprego de fubá de melhor qualidade protéica em farinhas mistas para produção de biscoitos. Ciência e Tecnologia de Alimentos, v. 25, n. 1, p. 63-71, 2005.

HORWITZ, W. Official methods of analysis of the Association of Official Analytical Chemists. 18 ed. Gaithersburg: AOAC, 2005a. p. 9-10. (Methods 942.23).

HORWITZ, W. Official methods of analysis of the Association of Official Analytical Chemists. 18 ed. Gaithersburg: AOAC, 2005b. p. 64-66. (Methods 961.15).

HORWITZ, W. Official methods of analysis of the Association of Official Analytical Chemists. 17 ed. Gaithersburg: AOAC, 2000. p. 15-18. (v. 2, Methods 985.35 e 984.27).

INSTITUTO BRASILEIRO DE GEOGRAFIA E ESTATÍSTICA - IBGE. Levantamento sistemático da produção agrícola. Rio de Janeiro: IBGE, 1993. (v. 5, n. 12).

INSTITUTO BRASILEIRO DE GEOGRAFIA E ESTATÍSTICA - IBGE. Levantamento sistemático da produção agrícola. Rio de Janeiro: IBGE, 1994. (v. 6, n. 12).

INSTITUTO BRASILEIRO DE GEOGRAFIA E ESTATÍSTICA - IBGE. Levantamento sistemático da produção agrícola. Rio de Janeiro: IBGE, 1995. (v. 7, n. 12).

INSTITUTO BRASILEIRO DE GEOGRAFIA E ESTATÍSTICA - IBGE. Levantamento sistemático da produção agrícola. Rio de Janeiro: IBGE, 1996. (v. 8, n. 12).

INSTITUTO BRASILEIRO DE GEOGRAFIA E ESTATÍSTICA - IBGE. Levantamento sistemático da produção agrícola. Rio de Janeiro: IBGE, 1997. (v. 9, n. 12).

INSTITUTO BRASILEIRO DE GEOGRAFIA E ESTATÍSTICA - IBGE. Levantamento sistemático da produção agrícola. Rio de Janeiro: IBGE, 1998. (v. 10, n. 12).

INSTITUTO BRASILEIRO DE GEOGRAFIA E ESTATÍSTICA - IBGE. Levantamento sistemático da produção agrícola. Rio de Janeiro: IBGE, 1999. (v. 11, n. 12).

INSTITUTO BRASILEIRO DE GEOGRAFIA E ESTATÍSTICA - IBGE. Levantamento sistemático da produção agrícola. Rio de Janeiro: IBGE, 2000. (v. 12, n. 12).

INSTITUTO BRASILEIRO DE GEOGRAFIA E ESTATÍSTICA - IBGE. Levantamento sistemático da produção agrícola. Rio de Janeiro: IBGE, 2001. (v. 13, n. 12).
IQBAL, A.; KHALIL, I. A.; SHAH, H. Nutritional yield and amino acid profile of rice protein as influenced by nitrogen fertilizer. Sarhad Journal of Agriculture, v. 19, n. 1, p. 127-134, 2003.

KHATOON, N.; PRAKASH, J. Nutritional quality of microwavecooked and pressure-cooked legumes. International Journal of Food Sciences and Nutrition, v. 55, n. 6, p. 441-448, 2004.

MAHALANABIS, D.; BHAN, M. K. Micronutrients as adjunct therapy of acute illness in children: impact on the episode outcome and policy implications of current findings. British Journal of Nutrition, v. 85, n. 2, p. 151-158, 2001.

MAIA, F. M. M. Composição e caracterização nutricional de três cultivares de Vigna unguiculata (L.) Walp: EPACE-10, Olho de ovelha e IPA-206. Fortaleza, 1996. 87 p. Dissertação (Mestrado em Bioquímica Vegetal) - Universidade Federal do Ceará - UFC.

MOREIRA-ARAUJO, R. S. R. et al. Impacto de salgadinho de alto valor nutritivo na situação nutricional de creches municipais de Teresina - PI. Nutrire: Revista Brasileira de Alimentação e Nutrição, v. 23, p. 7-21, 2002.

MOREIRA-ARAUJO, R. S. R.; ARAÚJO, M. A. M.; ARÊAS, J. A. Fortified food made by the extrusion of a mixture of chickpea corn and bovine lung controls iron-deficiency anaemia in preschool children. Food Chemistry, v. 107, n. 1, p. 158-164, 2008.

NATIONAL ACADEMIC PRESS - NRC. Dietary reference intakes: applications in dietary assessment. Washington: National Academic Press, 2001.

ORGANIZAÇÃO PAN AMERICANA DA SAÚDE - OPAS. Iron fortification: guidelines and recommendations for latin america and the Caribbean. Washington: OPAS; OMS, 2001.

PADOVANI, R. M. et al. Comparison of proximate, mineral and vitamin composition of common Brazilian and US foods. Journal of Food Composition and Analysis, v. 20, n. 8, p. 733-738, 2007.

PEDRERO, F. D. L.; PANGBORN, R. M. Evaluación sensorial de los alimentos: métodos analíticos. Mexico: Alhambra Mexicana, 1989. p. 103-107.

QUIN, F. M. Introduction. In: SING, B. B. et al. (Eds.). Advances in cowpea research. Ibadan: IITA; JIRCAS, 1997. p. 9-15.

TEIXEIRA, E.; MEINERT, E. M.; BARBETTA, P. A. Análise sensorial de alimentos. Florianópolis: UFSC, 1987.

UNIVERSIDADE DE SÃO PAULO - USP. Tabela Brasileira de Composição de Alimentos. Versão 4.1. São Paulo: USP. Disponível em: <http://www.fcf.usp.br/tabela>. Acesso em: Março 2005.

Van de WEERDHOF, T.; WIERSUN, M. L.; REISSENWEBER, H. Application of liquid chromatography in food analysis. Journal Chromatography, v. 83, p. 455-60, 1973. 